\title{
The effects of snowfall on a snow-ice-thickness distribution
}

\author{
J. L. Schramm, M. M. Holland, J. A. Curry \\ Department of Aerospace Engineering, Campus Box 429, University of Colorado, Boulder, CO 80309-0429, U.S.A.
}

\begin{abstract}
Snow falling uniformly on a distribution of ice thicknesses results in a distribution of snow-cover thicknesses. These snow depths depend on the amount of snowfall, the time of year at which it falls, and the thickness of the underlying ice. The effect of snowfall on snow-ice-thickness distribution is examined using a single-column ice ocean model. The time at which snow begins to accumulate, and melt ponds and leads freeze, affects the surface albedo. The rate of snowfall affects ice-growth rates and, as a result, the ice-thickness distribution. During the period of rapid ice growth between the autumn freeze and mid-winter, snow falling on newly formed ice is rapidly depleted due to sublimation. Snow falling on thicker ice remains throughout the winter to create a source of meltwater for ponds and runoff into the ocean.
\end{abstract}

\section{INTRODUCTION}

Due to lack of snowfall data in the Arctic, many previous thermodynamic sea-ice models have used monthly climatological snowfall rates. The prescribed snowfall rates assumed by Maykut and Untersteiner (1971) (hereafter referred to as MU) have been widely used (e.g. Semtner, 1976; Parkinson and Washington, 1979). These accumulation rates were chosen to represent the annual cycle of snowfall in the central Arctic, but did not include precipitation during the melt season. Ebert and Curry (1993) used monthly snowfall rates derived from climatological data from stationary and drifting stations (Vowinckel and Orvig, 1970) (hereafter referred to as VO). These data included summertime precipitation.

Previous models that have included an ice-thickness distribution have ignored snowfall (e.g. Thorndike and others, 1975; Hibler, 1980; Thomson and others, 1988). Björk (1992), while including an ice-thickness distribution, neglected the thermal inertia of snow cover. More recently, Flato and Hibler (1995) have included a snow-thickness distribution, with monthly averaged snowfall rates. They note that varying these snowfall amounts by $\pm 50 \%$ increases or decreases the mean ice thickness by $<25 \mathrm{~cm}$, while completely eliminating the snowfall increased the mean ice thickness by about $50 \mathrm{~cm}$.

In a study emphasizing inter-annual variability, Ross and Walsh (1987) compared the results of a dynamic thermodynamic sea-ice model run with monthly snowfall fields from 1977 and 1979 to the same model run with the climatological MU snowfall. They found that with the variable snowfall, the model could simulate large portions of the inter-annual variability in the summer surface albedo. The MU snowfall resulted in a thinner snow cover at the end of winter, and an earlier onset of the melt season. Thinner ice occurred at the end of the melt season.

In this study, we examine the effects of the $\mathrm{VO}$ and $\mathrm{MU}$ snowfalls on the snow-ice thickness distribution. A randomly varying annual cycle of snowfall is also introduced to simulate individual snowfall events as well as the inter- vening snow-free periods. First, the three annual cycles of snowfall and their effect on the area-averaged ice properties are discussed. Second, the effect of snowfall on the ice-thickness distribution is examined, and the annual cycle of snow cover for each ice-thickness bin is discussed. Finally, the processes affecting snow-cover mass balance and their dependence on ice thickness is examined.

\section{MODEL DESCRIPTION}

In general, the sea-ice- ocean model is a single-column representation of an ice sheet at about $80^{\circ} \mathrm{N}$, with a domain large enough to represent an ice-thickness distribution. The ice-thickness distributions of level and ridged ice are calculated from a 100 year model run, and separated into 25level and 15-ridged ice-thickness categories. Both ice-thickness distributions include first-year ice (FYI) at the thin end, and multi-year ice (MYI) at the thick end. Here, FYI is defined as ice that has not survived a melt season. Each ice category is described by surface characteristics (area, snow cover, pond fraction and depth, surface temperature, and age) and interior ice properties (ice thickness, ice temperature, salt content and brine pockets), with each category evolving thermodynamically and independently from the others. The model also includes parameterizations of export and ridging (Björk, 1992), an interactive bulk ocean-mixed layer (Gaspar, 1988), and melt-pond and albedo parameterizations (Ebert and Curry, 1993). A more detailed description of the ice-thickness distribution model and the ocean mixed-layer model can be found in Schramm and others (in press) and Holland and others (in press).

Particular to this study are the processes acting to remove the snow cover from the ice-thickness distribution. These processes and the modeling of the snow cover will be described briefly. The direct and diffuse albedos of the snow cover depend on whether the snow is dry or melting, and are calculated following Ebert and Curry (1993). The snow density is assumed to be $330 \mathrm{~kg} \mathrm{~m}^{-3}$ all year. The snow cover has one interior temperature point to allow for the storage of heat (Ebert and Curry, 1993). Snow falls evenly on all ice- 
thickness categories; snow redistribution by wind is not included. Reduction of the snow cover by sublimation is proportional to the latent heat flux at the surface. It is assumed that the snow cover on the thin ice being ridged falls into the ocean mixed layer. The snow cover on any ice that is exported is also exported. If the weight of the snow cover causes the ice-snow interface to sink below the water level, this saturated snow becomes ice.

When snowmelt begins, $85 \%$ of the meltwater is allowed to run off into the ocean while the other $15 \%$ is held in a reservoir until the entire snow cover has melted. This reserved water is then available to form melt ponds. Any snow that falls during the melt season melts upon contact with the surface, and runs off or is ponded in the ratio described above. Evaporation removes the snow cover in proportion to the latent heat flux but, due to the short period in which snow cover exists while the surface temperature is above the melting point, evaporation removes little snow mass during the year.

\section{SENSITIVITY TO THE ANNUAL GYCLE OF SNOWFALL}

To examine the sensitivity of the single-column ice-ocean model to snowfall, three annual cycles of snowfall are considered. The first annual cycle is derived from climatological data obtained from drifting stations in the vicinity of $80^{\circ} \mathrm{N}$ (Vowinckel and Orvig, 1970). These values are multiplied by 1.6 to account for the gauge measurements that underestimate the snowfall by about $60 \%$ (Ebert and Curry, 1993). This annual cycle of snowfall produces a total annual snowfall of about $50 \mathrm{~cm} \mathrm{a}^{-1}$ (Fig. la, solid). In this case, snowfall continues throughout the summer, melts upon contact with the surface, and increases ponded and runoff meltwater.
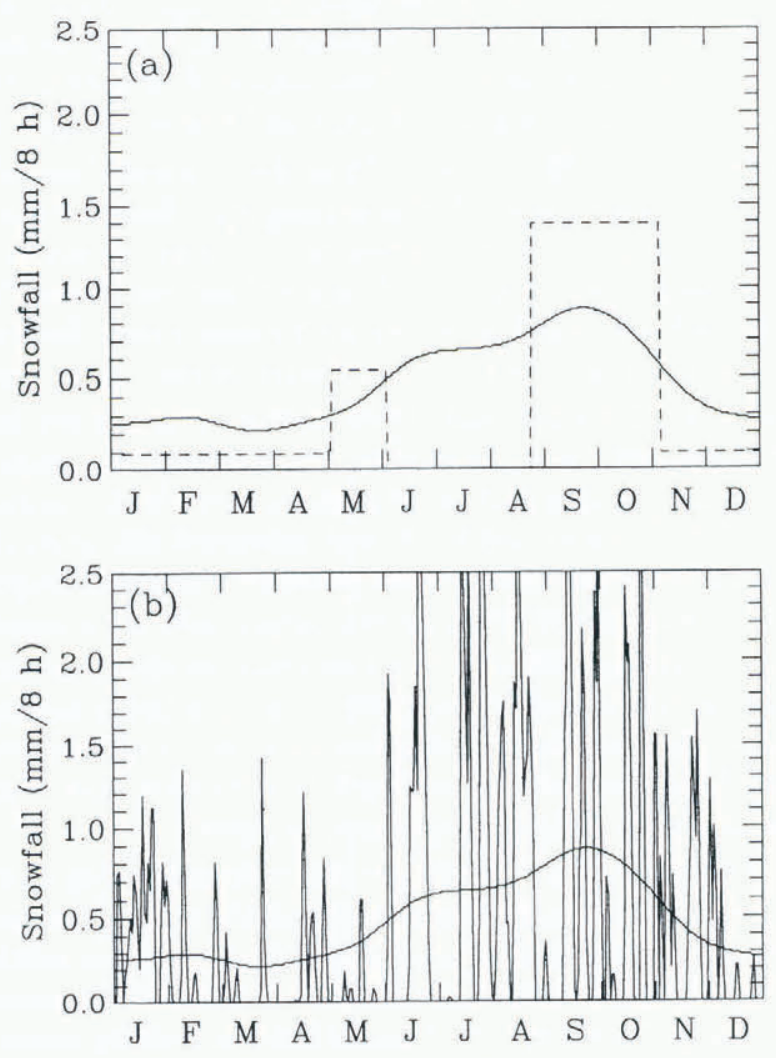

Fig. 1. Annual cycle of snowfall in $\mathrm{mm} / 8$ hours from (a) Vowinckel and Orvig (1970) (solid) and Maykut and Untersteiner (1971) (dashed) and (b) a randomly varying snowfall.
The second pattern of snowfall is described by Maykut and Untersteiner (1971). The values of MU snowfall were chosen to represent the annual cycle of surface snow cover, and capture the rapid autumn accumulation of snow as well as the onset of the melt season (Fig. la, dashed). There is no snowfall during the melt season, and the total annual snowfall is $40 \mathrm{~cm} \mathrm{a}^{-1}$. With the onset of MU snowfall fixed from August 20, the length of the bare-ice season is extended when compared to the VO model. For the third annual cycle of snowfall (hereafter referred to as RV), random variation was applied to the VO snowfall to capture better the snowfall events and snow-free periods that are more representative of a realistic annual cycle of snowfall (Fig. 1b). This annual cycle gives a total annual snowfall of $55 \mathrm{~cm} \mathrm{a}^{-1}$.

\section{Area-averaged ice properties}

The area-averaged annual cycles of various ice-surface properties for the three different snowfalls are shown in Figure 2. The largest variation in ice thickness (Fig. 2a) is about
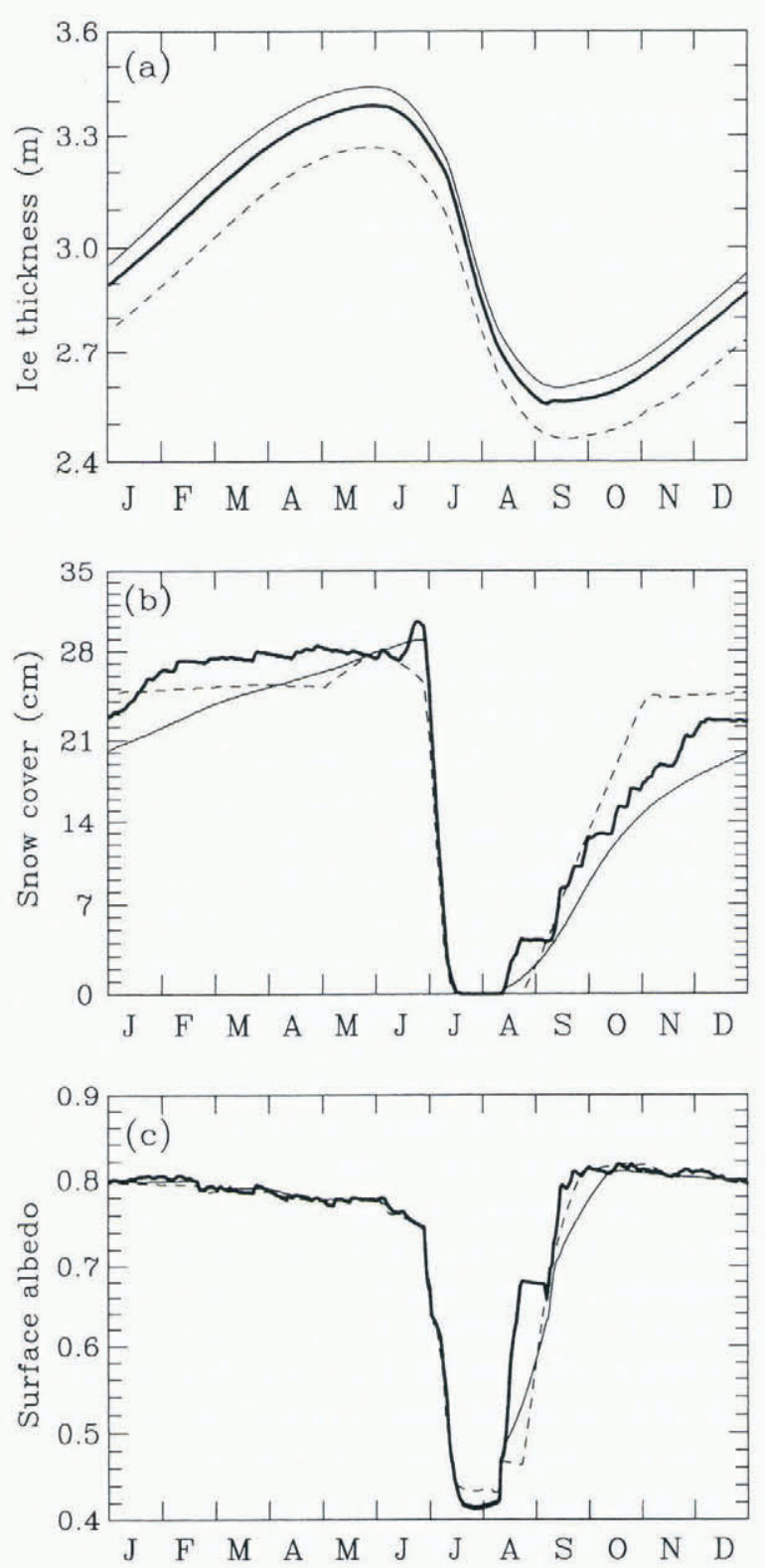

Fig. 2. The area-averaged annual cycles of ( a ) ice thickness, ( $b$ ) snow cover and (c) surface albedo for the Vowinckel and Orvig (1970) snowfall (solid), the Maykut and Untersteiner (1971) snowfall (dashed) and the randomly varying snowfall (bold). 

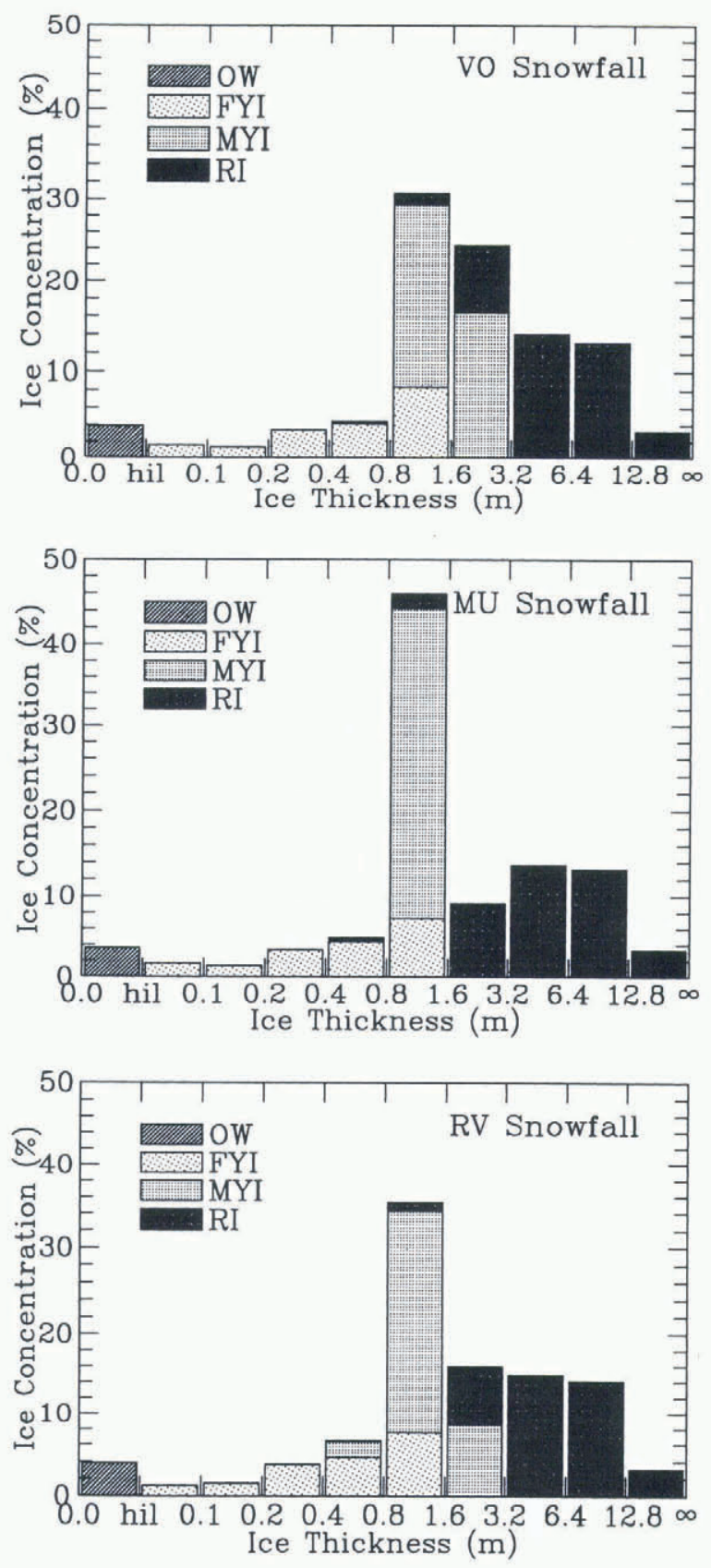

Fig. 3. Annually averaged ice-thickness distribution for (a) the Vowinckel and Orvig (1970) snowfall, (b) the Maykut and Untersteiner (1971) snowfall and (c) the randomly varying snowfall. The ice types include open water ( $O W$ ), firstyear ice (FII), multi-year ice (MYI), and ridged ice (RI). Ice thinner than $h i_{l}=0.5 \mathrm{~cm}$ is considered to be open water.

$20 \mathrm{~cm}$ between VO (solid) and MU (dashed) snowfalls. This is due to the rapid accumulation of snow from the $\mathrm{MU}$ snowfall, which produces a thicker snow cover and has an insulating effect on the ice (Fig. 2b). The RV snowfall (bold) allows the snow cover to increase as rapidly as the MU snowfall, due to a large snowfall event in mid-August. By late autumn, the rate of change of the snow cover is between that of the $\mathrm{VO}$ and $\mathrm{MU}$ snowfalls. The surface temperature is relatively unchanged by snowfall, except for minor variations before and after the melt season.

The surface albedo is very sensitive to the timing of the onset of snow accumulation, and to the freezing of melt ponds and leads (Fig. 2c). MU snowfall, which allows a longer melt season, shows a distinct period of bare ice in late August, when the melt ponds are frozen over but the snow is
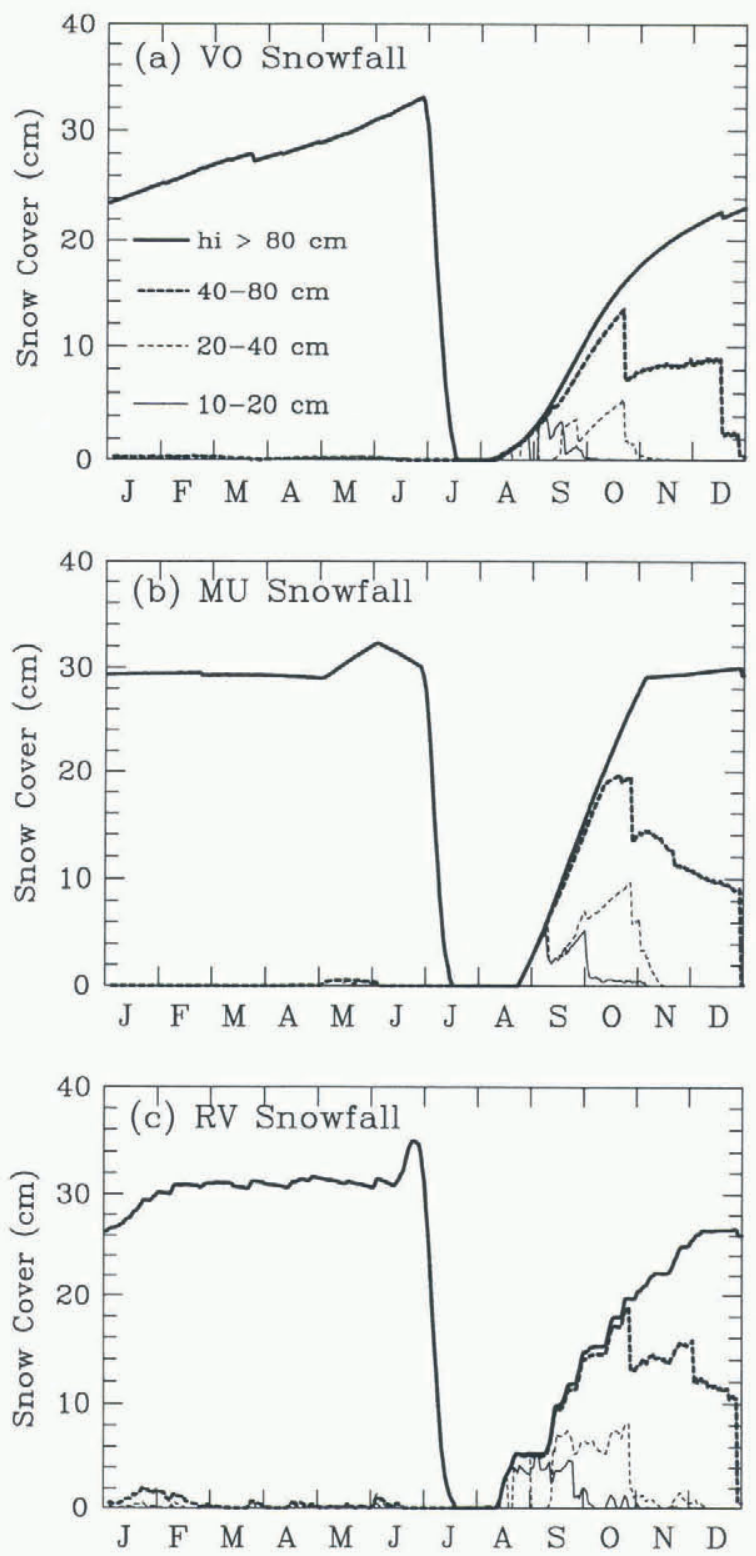

Fig. 4. Annual cycle of the area-averaged snow cover over selected ice-thickness bins resulting from (a) Vowinckel and Orvig (1970) snowfall, (b) Maykut and Untersteiner (1971) snowfall and $(c)$ randomly varying snowfall.

not yet accumulating. The area-averaged albedo of this bare ice is about 0.47 . This period of bare ice is notably absent for the VO and RV snowfalls, since the onset of snow accumulation coincides with the freezing of melt ponds. The gradual increase in surface albedo for the VO snowfall coincides with the gradual increase in snow cover. The albedos for the three snowfalls are similar when the leads freeze over in early September.

\section{Ice-thickness distribution}

Whereas snowfall affects the area-averaged ice properties, it is not clear how the effects of snowfall vary with ice thickness. Considering a distribution of ice thicknesses makes these effects more apparent, especially in the thinner ice. The annually averaged ice-thickness distributions for the three snowfalls are shown in Figure 3. For presentation purposes, the 25-level and 15-ridged thickness categories have been sorted into a single set of thickness bins, arranged so as to provide greater resolution in the thin ice where surface properties change most rapidly with thickness. The ice in 
(a) VO Snowfall
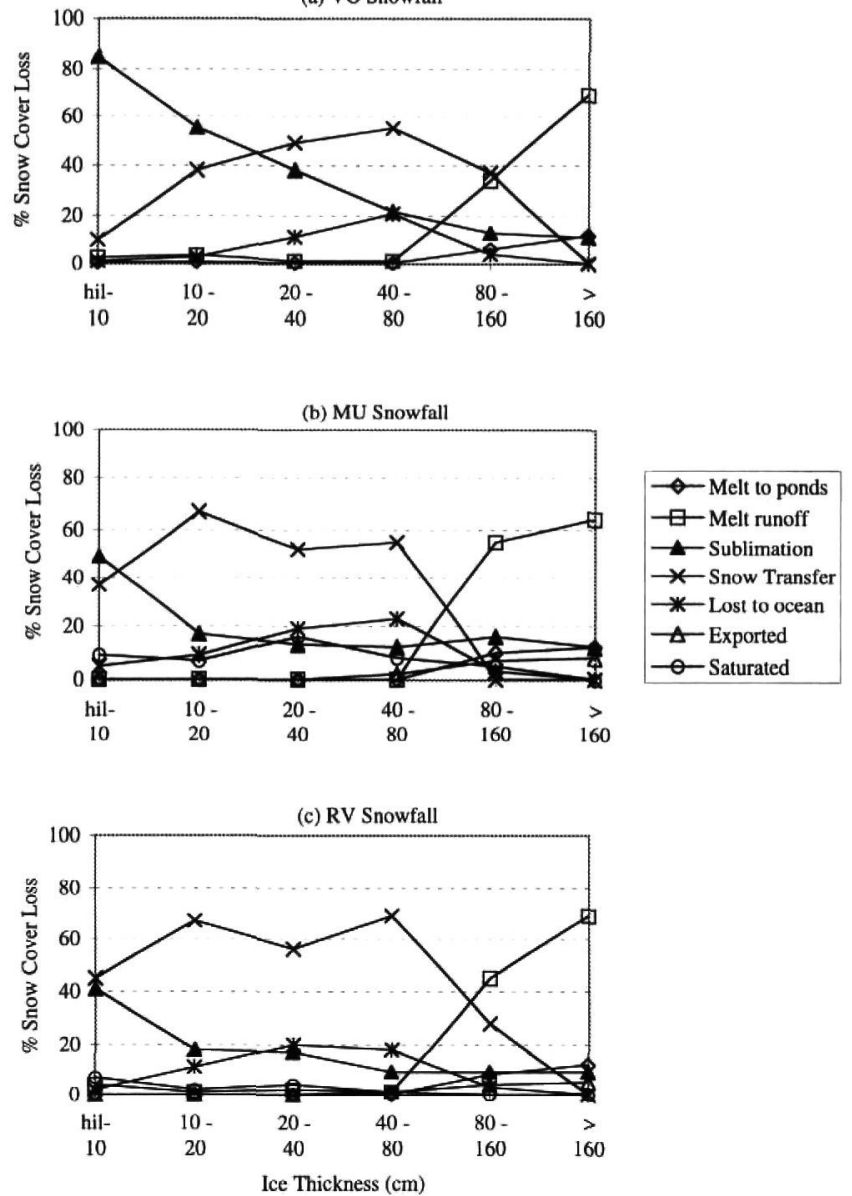

Fig. 5. Variation of snow-rower mass sinks with iec thickness for (a) Vowinckel and Orvig (1970) snowefall. (b) Maykut and Untersteiner (IS7l) snowefall and (c) randomly uarving snotefall.

each bin is also separated into open water (OW), FYl, MYl, and ridged ice (RI). Ice thinner than $h i_{i}=0.5 \mathrm{~cm}$ is considered to be open water. For all snowfalls, the next four bins are mainly FYL. The area and thickness of this ice are determined mainly by the freezing of OW and ice growth. Some of this thin ice is ridged and creates the ridged ice in the last five bins. The ridged ice-thickness distribution is also not sensitive to the annual cycle of snowfall.

Snowfall has the largest effect on the MYI distribution. The ice bins in this thickness range $(80.320 \mathrm{~cm})$ exchange area all year due to melting and freczing, and are not affected by ridging. The MYI from the VO and RV snowfalls covers a large range of thicknesses, indicating a significant change in thickness due to freezing and melting. The larger snow cover resulting from the MU snowfall limits ice growth, limiting the areal exchange between these bins. In the next section, the annual cycle of snow cover for each of these bins, and the snow-cover mass sinks are examined.

\section{Snow-cover mass sinks}

The annual cycles of snow cover resulting from the VO, $\mathrm{MU}$, and RV snowfalls are shown in Figure 4 for selected ice-thickness bius, with ice thicker than $80 \mathrm{~cm}$ averaged into a single bin. There is a distinct difference in the annual cycles of ice thicker than $80 \mathrm{~cm}$ (bold solid line) and those thinner than $80 \mathrm{~cm}$; the snow cover does not increase continuously with ice thickness. While all ice thicknesses begin to accumulate a snow cover in the autumn, snow is depleted so rapidly from ice thinner than $80 \mathrm{~cm}$ that by the end of December, there is no discernable snow cover.

As the open water freezes over in the fall and throughout 
the winter, thin rapidly growing ice is created. As this ice grows enough to move into the adjacent thickness bin, the overlying snow cover is also transferred. We refer to this process as "snow transfer". Figure 5 shows the most important snow mass sinks for the three snowfalls. Due to the similar thermodynamics of the thicker ice $(>160 \mathrm{~cm})$, the snow sinks are only shown for ice thinner than $160 \mathrm{~cm}$. Processes removing $<2 \%$ of the annual snow cover are not shown, but include evaporation, and lateral melting and freezing. For the VO snowfall, sublimation is very efficient at removing snow from the thinnest ice due to the slow accumulation (Fig. 5a). This indicates that the rate of mid-winter sublimation is greater than the VO snowfall rate of $1 \mathrm{~mm} / 8$ hours, which would require a latent heat flux greater than $11 \mathrm{Wm}^{-2}$. Latent heat fluxes of this magnitude are present on ice thinner than $40 \mathrm{~cm}$, and are in agreement with those calculated by Maykut (1978) over various ice thicknesses. Snow transfer becomes more important for the first four thickness bins, where ice growth is largest, then reaches a maximum for the $40-80 \mathrm{~cm}$ thickness bin. This is where the ice is still thin enough to be growing, but thick enough to have a substantial snow cover to transfer. Most snow is lost to the ocean via ridging for ice $20-80 \mathrm{~cm}$. For ice thicker than $80 \mathrm{~cm}$, surface melting becomes an important process for snow removal as it has a substantial snow cover.

The thicker snow cover resulting from the MU snowfall reduces the latent heat flux at the surface by moving the snow surface away from the relatively warmer snow-ice interface and decreasing the difference between air- and surface-specific humidities. This reduces sublimation and allows more snow to be transferred as the ice grows (Fig. $5 b)$. The weight of the thicker snow submerges the snow-ice interface, saturating this snow. Saturation is insignificant for the VO snowfall. The thicker snow cover also allows more snow to be lost to the ocean via ridging. More meltwater is produced for the $80-160 \mathrm{~cm}$ bin due to the thicker snow cover present at the onset of the melt season. Less meltwater is produced for ice thicker than $160 \mathrm{~cm}$ due to the lack of summer precipitation. The snow mass sinks for the RV snowfall, and their variation with ice thickness, are between those of the VO and MU snowfalls due to the rapid growth of snow cover in autumn and the more gradual snow accumulation that follows.

\section{CONGLUSIONS}

The snow-ice-thickness distributions resulting from three different annual cycles of snowfall have been examined. It was found that the annual cycle of the area-averaged ice thickness was sensitive to the rate of autumn snow accumulation. The MU snowfall, with the most rapid accumulation, has the thinnest area-averaged ice thickness. This is due to the insulating effect of the thicker snow cover, which limits ice growth, particularly for MYI.

The surface albedo is sensitive to the timing of the onset of snow accumulation and melt-pond freezing. There is a 13 day period between these two events for the MU snowfall, maintaining the albedo at that of bare ice. These events are simultaneous for the VO and RV snowfalls, causing the surface albedo to increase immediately to the dry-snow value. The timing of the onset of snow accumulation can considerably lengthen or shorten the length of the melt season.

Processes acting to remove the snow cover vary with ice thickness. For thin ice $(<80 \mathrm{~cm})$, snow cover is rapidly removed by sublimation and via growth of the underlying ice to a thicker bin. The rapid accumulation of the MU snow cover allows the saturation of $10-20 \%$ of the snow cover on thin ice. Snow cover on the thicker ice $(>80 \mathrm{~cm})$ is removed mainly by melting. Although snow redistribution by wind was not included in this study, this process would further reduce the snow cover on the thinner ice by transferring it to the thicker ice. Wind and snowfall measurements on a variety of temporal and spatial scales are necessary to model properly the annual and inter-annual variability of surface albedo, melt season, and snow cover, and accurately to simulate the ice-thickness distribution.

\section{ACKNOWLEDGEMENTS}

This research was supported by NSF OPP-9504261. We would like to thank G. Flato for his helpful comments and suggestions on the manuscript.

\section{REFERENCES}

Bjök, G. 1992. On the response of the equilibrium thickness distribution of sea ice to ice export, mechanical deformation, and thermal forcing with application to the Arctic Ocean. J. Geophys. Res., 97 (C7), 11,287-11,298.

Ebert, E. E. and J. A. Curry. 1993. An intermediate one-dimensional thermodynamic sea ice model for investigating ice-atmosphere interactions. J. Geophys. Res., 98 (C6), 10,085-10,109.

Flato, G. M. and W. D. Hibler, III. 1995. Ridging and strength in modeling the thickness distribution of Arctic sea ice. 7. Geophys. Res., 100 (C9), $18,611-18,626$.

Gaspar, P. 1988. Modelling the seasonal cycle of the upper ocean. 7. Phys. Oceanogr., 18 (2), 161-180.

Hibler, W. D., III. 1980. Modeling a variable thickness sea ice cover. Mon. Weather Rer., 108 12), 1943-1973.

Holland, M. M., J. A. Curry and J. L. Schramm. In press. Modeling the thermodynamies of a distribution of sea ice thicknesses. Part II. Sea ice/ocean interactions. J. Geophys. Res.

Maykut, G. A. 1978. Energy exchange over young sea ice in the central Arctic. 7. Geophys. Res., 83 (C7), 3646-3658.

Maykut, G. A. and N. Untersteiner. 1971. Some results from a time-dependent thermodynamic model of sea ice. J. Geophys. Res., 76 (6), 1550-1575.

Parkinson, C. L. and W. M. Washington. 1979. A large-scale numerical model of sea ice. F. Geophys. Res., $84(\mathrm{Cl}), 311-337$.

Ross, B. and J. E. Walsh. 1987. A comparison of simulated and observed fluctuations in summertime Arctic surface albedo. f. Geophys. Res., $92(\mathrm{Cl} 2$, $13,115-13,125$

Schramm, J. L., M. M. Holland and J. A. Curry. In press. Modeling the thermodynamics of a distribution of sea ice thicknesses. Part I. Model description and validation. J. Geophys. Res.

Semtner, A. J., Jr. 1976. A model for the thermodynamic growth of sea ice in numerical investigations of climate. J. Phys. Oceanogr., 6 (5), 379389.

Thomson, N. R., J. F. Sykes and R. F. McKenna. 1988. Short-term ice motion modeling with application to the Beaufort Sea, 7. Geophys. Res., 93 C6), 6819-6836.

Thorndike, A. S., D. A. Rothrock, G. A. Maykut and R. Colony. 1975. The thickness distribution of sea ice. 7. Geophys. Res., 80 (33), 4501-4513.

Vowinckel, E. and S. Orvig. 1970. The climate of the north polar basin. In Orvig, S., ed. Climates of the polar region.s. New York, Elsevier, 129252. (World Survey of Climatology 14. 